\title{
Comparison of the microbial diversity and abundance between the freshwater land-locked lakes of Schirmacher Oasis and the perennially ice-covered Lake Untersee in East Antarctica
}

\author{
Jonathan Huang ${ }^{\mathrm{a}}$, Richard B. Hoover ${ }^{\mathrm{b}}$, Ashit Swain ${ }^{\mathrm{c}}$, Chris Murdock ${ }^{\mathrm{d}}$, Asim K. Bej ${ }^{\mathrm{a}^{*}}$ \\ ${ }^{\text {a }}$ The University of Alabama at Birmingham, Birmingham, AL 35294, U.S.A. \\ ${ }^{b}$ NASA/NSSTC, SD50, 320 Sparkman Dr., Huntsville, AL 35805, U.S.A. \\ ${ }^{\mathrm{C}}$ National Center for Antarctic and Ocean Research, Head land Sada Vasco-da-Gama, \\ Goa, 403 804, INDIA \\ ${ }^{\mathrm{d}}$ Jacksonville State University, Jacksonville, AL, 36265, U.S.A.
}

*Corresponding author: abej@uab.edu; phone 1205934 9857; fax 12059756097

\begin{abstract}
Extreme conditions such as low temperature, dryness, and constant UV-radiation in terrestrial Antarctica are limiting factors of the survival of microbial populations. The objective of this study was to investigate the microbial diversity and enumeration between the open water lakes of Schirmacher Oasis and the permanently ice-covered Lake Untersee. The lakes in Schirmacher Oasis possessed abundant and diverse group of microorganisms compared to the Lake Untersee. Furthermore, the microbial diversity between two lakes in Schirmacher Oasis (Lake L27C and L47) was compared by culture-based molecular approach. It was determined that L27Chad a richer microbial diversity representing 5 different phyla and 7 different genera. In contrast L47 consisted of 4 different phyla and 6 different genera. The difference in microbial community could be due to the wide range of $\mathrm{pH}$ between $\mathrm{L} 27 \mathrm{C}$ ( $\mathrm{pH} \mathrm{9.1)} \mathrm{and} \mathrm{L} 47$ ( $\mathrm{pH}$ 5.7). Most of the microbes isolated from these lakes consisted of adaptive biological pigmentation. Characterization of the microbial community found in the freshwater lakes of East Antarctica is important because it gives a further glimpse into the adaptation and survival strategies found in extreme conditions.
\end{abstract}

Keywords: Antarctica, Schirmacher Oasis, , Lake Untersee, Microorganisms, Biodiversity, Lakes, Phylogenetics, 16S rRNA, Microbial Taxonomy, Culture-dependent methodology, 16S rRNA

\section{INTRODUCTION}

Antarctica is one of the coldest and driest continent on Earth and microorganisms inhabiting on this icy continent are referred as extremophiles. These microorganisms often exhibit unique adaptive and survival capability, and play an essential role in nutrient recycling for the Antarctic ecosystem. It was originally hypothesized that due to the extreme cold condition the Antarctic continent is devoid of life.To our knowledge, Erik Ekelöf (1908a, b) ${ }^{1,2}$ was the first to report microbial existence in Antarctica. This was later confirmed by other scientists ${ }^{3-9}$ by describing microbial life found in Antarctic soil and water. Due to the development of more sophisticated techniques, molecular based approaches are currently used to determine microbial diversity in Antarctica. In particular, 16S rRNA gene has become the standard taxonomical gene for bacterial identification. Using these techniques it is now known that Antarctica freshwater lakes possess a moderately rich microbial population (Huang et al., in preparation) ${ }^{10}$.

The primary objective of this study is to determine the microbial diversity and enumeration found freshwater land-locked lakes of Schirmacher Oasis and the perennially ice-covered Lake Untersee in the Dronning Maud Land of East Antarctica. The open water lakes in Schirmacher Oasis allows for mixing and cross-mixing of microorganisms among lakes through snow melt, surface channels, and catabolic wind. Lake Untersee, on the other hand, is a closed water system, which is perennially frozen and thus there islimited amount of mixing of microorganisms. Another objective is to use culture-dependent methodology 
along with molecular techniques to determine the microbial diversity and abundance between two of the freshwater land-locked lakes, L27C and L47 in order to see if there is any correlation in microbial diversity between the two freshwater land-locked lakes.

\section{MATERIAL AND METHODS}

\subsection{Study Site}

2.1.1. Schirmacher Oasis. The Schirmacher Oasis is $3 \mathrm{~km}$ wide, $20 \mathrm{~km}$ long and consists of over 180 lakes (Matondkar, 1986) $)^{11}$ The Russian Antarctic Station Novolazarevskaya (7046'04” S and $11^{\circ} 49^{\prime} 54^{\prime \prime}$ E) and the Indian Station Maitri $\left(70^{\circ} 45^{\prime} 57^{\prime \prime S}, 11^{\circ} 44^{\prime} 09^{\prime \prime} \mathrm{E}\right)$ are located in the Schirmacher Oasis. Within this Oasis, there are two lakes, L27Cand L47, which are both formed by melt water from the Schirmacher glacierduring the summer months (Figure 1). These lakes in Schirmacher Oasis are open water systems and expected to experience cross-mixing of the microorganisms either through the melting of the snow during summer months or by near continuous high wind $\left(15-100 \mathrm{~km} \mathrm{~h}^{-1}\right)$. The open water system is exposed to seasonal and often diurnal freezing and thawing cycles; continuous solar radiation during summer months and completely frozen and often covered with snow during the winter months.

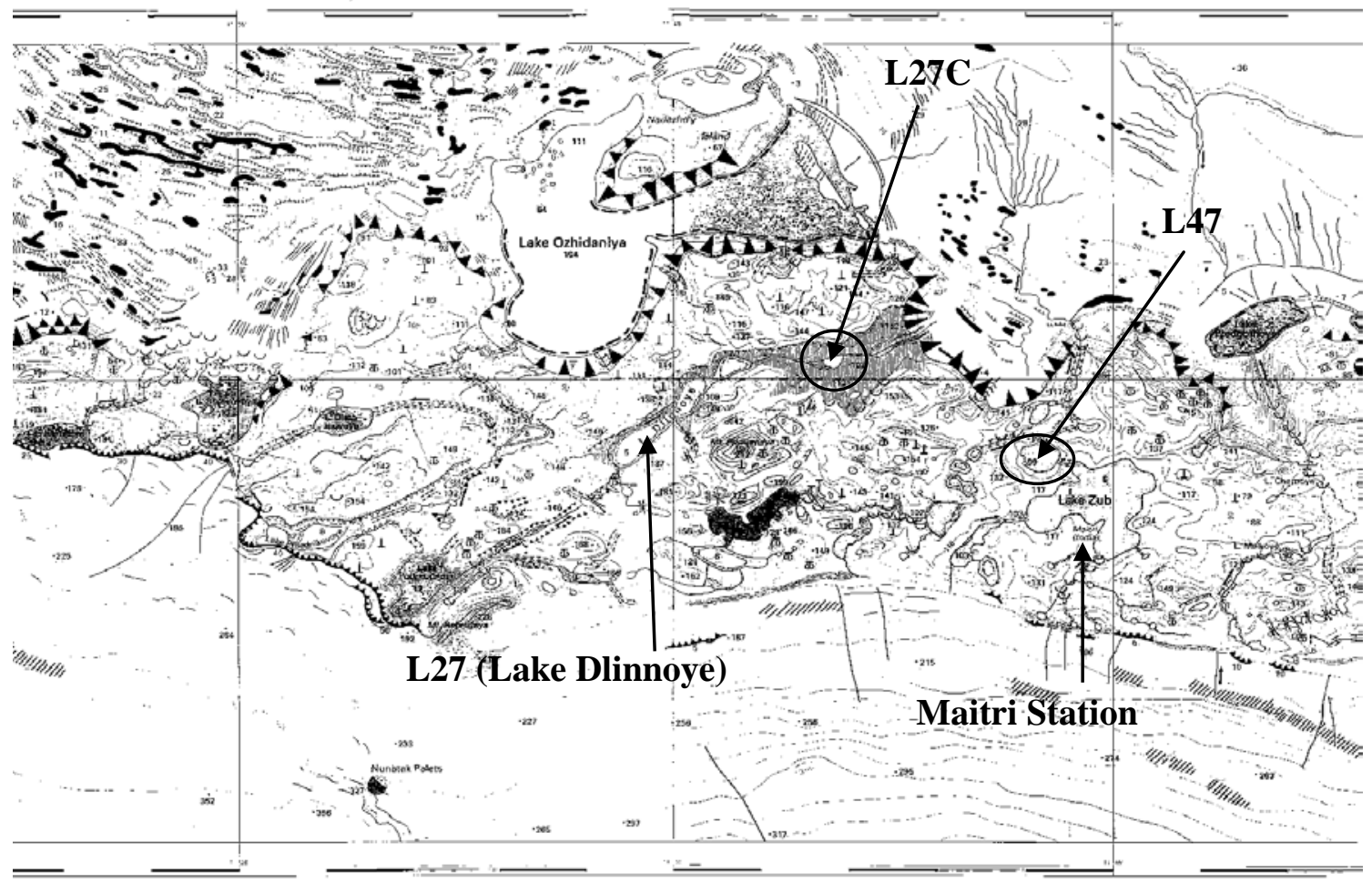

Figure 1: Map of Schirmacher Oasis with the lakes of interest circled (L27Cand L47). Water samples from L27Cand L47 were collected during the 2008 Tawani International Antarctic expedition.

2.1.2. Lake Untersee. Lake Untersee is a perennially ice-covered, ultra-oligotrophic, lake in the Otto-vonGruber-Gebirge (Gruber Mountains) of Central Dronning Maud Land (Figure 2). Lake Untersee is a closed freshwater system due to the lake being perennial ice-covered thus there is little to none intermixing between the outside environment and Lake Untersee. 


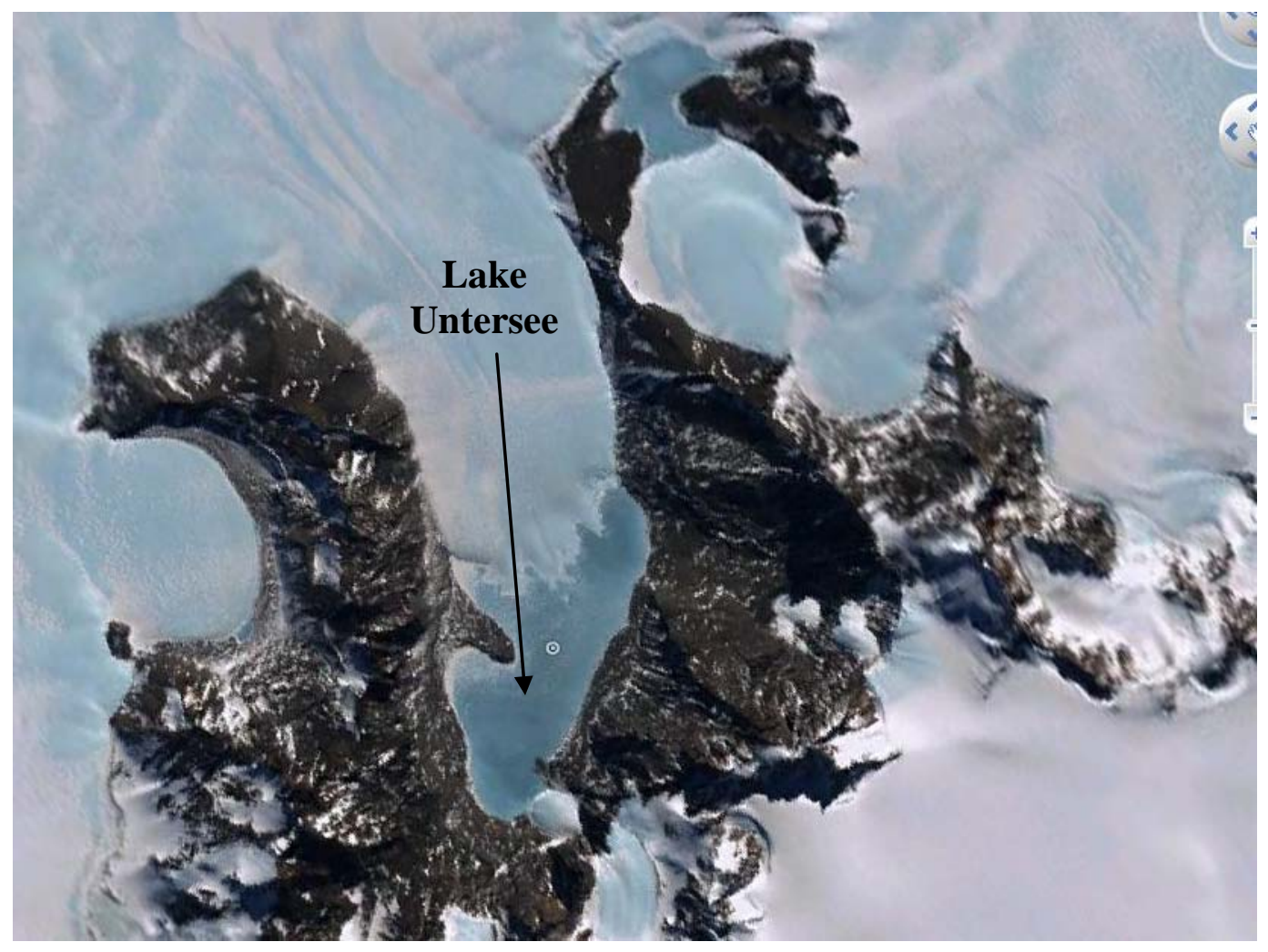

Figure 2: Map of Lake Untersee. Samples were collected from Lake Untersee during the 2008 Tawani International Antarctic expedition (obtained from Google Earth).

\subsection{Sampling.}

2.2.1. Schirmacher Oasis. Water samples were collected in sterile Whirl-Pak ${ }^{\mathrm{TM}}$ bags and sample bottles from the surface ( 3-4 inches from the water surface) or by lightly scrapping the rock surfaces where normally the melting of the ice occurs during the day time and freezes during the night hours. The physicochemical parameters of local ecosystems ( $\mathrm{pH}$, salinity, conductivity and temperature) were measured in situ and documented at the moment of sampling for both L27C and L47 (Table 1). The samples were transported frozen to UAB. All samples were stored at $-20^{\circ} \mathrm{C}$ until used. Triplicate samples were collected and used for all experiments.

Table 1: Physical conditions and descriptions of Lake Tawani and L47 located in Schirmacher Oasis, Antarctica

\begin{tabular}{|c|c|c|}
\hline Sample ID & L27C & L47 \\
\hline GPS location & $\begin{array}{l}\text { S70 } 45.257^{\prime} \\
\text { E11 } 41.419^{\prime}\end{array}$ & $\begin{array}{l}\text { S70 } 45.693 \\
\text { E11 }\end{array}$ \\
\hline Sample type & Water+algae/Moss & Water \\
\hline pH & 9.1 & 5.7 \\
\hline Water Temp & $0.4^{\circ} \mathrm{C}$ & $-0.3^{\circ} \mathrm{C}$ \\
\hline $\mathrm{UV}$ radiation $\left(\mathrm{mW} / \mathrm{cm}^{2}\right)$ & 0.3 & 1.40 \\
\hline Refractive Index & $<1.333$ & $<1.333$ \\
\hline
\end{tabular}


2.2.2. Lake Untersee. Water samples were collected using a 2.2L Teflon Kemmerer Sampler Bottle (1520-C22) with messenger from Wildlife Supply Company, Yulee, Florida. Samples of the water column were taken at depths of $10,20,45,55,65,70,80$ and 90 meters beneath the surface of the perennial ice sheet of Lake Untersee. Sediment samples were obtained from the bottom of the Lake Untersee deep anoxic trough with 602-202 Ekman Tall Sampler (6X6X9) from Rickly Hydrological Co., Columbus, Ohio.

\subsection{S rRNA gene culture-dependent study.}

2.3.1. Plating on R2A agar and PCR parameters. $50 \mu$ of sample from L27C was plated onto R2A agar and was grown at $15^{\circ} \mathrm{C}$ until fully formed colonies appeared on the plate ( 2 week). Individual colonies were picked based on the morphologically distinct colonies (color, shape, texture, size, opacity) and subcultured onto fresh R2A plates. DNA from individual colonies on the R2A agar plates were randomly selected and boiled for 10 min to release DNA and quickly transferred onto ice.

An aliquot $(3 \mu \mathrm{l})$ of the boiled sample was PCR amplified targeting the eubacterial 16S rRNA gene using the forward primer 18F (5'-AGAGTTTGATCATGGCTCAG-3') and reverse primer 1509R (5'GGTTACCTTGTTACGACTT-3') (Martinez-Murcia et al., 1999). ${ }^{12}$ PCR parameters were used as follows: $5 \mathrm{U}$ of Taq DNA polymerase (Promega), 1X PCR buffer (5 mM Tris.Cl, pH 8.9; $5 \mathrm{mM} \mathrm{KCl,} 2.5 \mathrm{mM}$ $\mathrm{MgCl}_{2}$ ), $200 \mu \mathrm{M}$ each of the dNTPs, $0.5 \mu \mathrm{M}$ of each of the oligonucleotide primers, and $3 \mu \mathrm{l}$ of the template DNA. The reaction volume was adjusted to $25 \mu \mathrm{l}$ with sterile distilled water. The PCR cycling parameters consisted of an initial denaturation step at $95^{\circ} \mathrm{C}$ for 5 minutes followed by 25 cycles of amplification with denaturation at $95^{\circ} \mathrm{C}$ for $1 \mathrm{~min}$, primer annealing at $55^{\circ} \mathrm{C}$ for $1 \mathrm{~min}$ and primer extension at $72^{\circ} \mathrm{C}$ for $2 \mathrm{~min}$. Following 25 cycles of amplification, a final extension step was at $72^{\circ} \mathrm{C}$ for 10 minutes. The samples were stored at $4^{\circ} \mathrm{C}$ until used.

2.3.2. Construction and analyses of $16 \mathrm{~S}$ rRNA gene clone libraries.The amplified PCR products were ligated overnight onto the pGEM-T ${ }^{\mathrm{TM}}$ Easy vector system (Promega). Plasmid DNA was transformed into

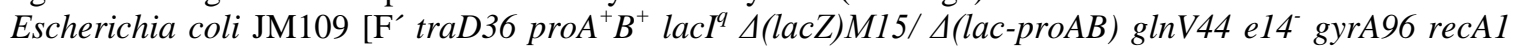
relA1 endA1 thi hsdR17] competent cells. The putative transformed white colonies were on Luria-Bertani agar plates supplemented with ampicillin $(50 \mu \mathrm{g} / \mathrm{mL})$ antibiotic, $100 \mu \mathrm{L}$ of IPTG $(100 \mathrm{mM})$ and $20 \mu \mathrm{l}$ of Xgal $(40 \mathrm{mg} / \mathrm{ml})$. These white colonies were then picked and checked for the correct size by PCR. Plasmids were then extracted by Genscript Quickclean ${ }^{\mathrm{TM}} 5 \mathrm{M}$ Miniprep Kit (Genscript) and sent for sequencing at UAB Center for AIDS Research (CFAR).

Phylogenetic analyses were done by MEGA 4 software (http://www.megasoftware.net/). DNA sequences were aligned and trimmed using CLUSTALW found in MEGA 4 software. Phylogenetic trees were constructed using the Neighbor-Joining (NJ) method of analysis. Furthermore bootstrap sampling method was chosen to determine the reliability of each phylogenetic tree.

\subsection{Microbial enumeration by direct plate count.}

Culturable heterotrophic bacteria were enumerated by the spread plate method. Fifty microliters sample was plated on R2A agar plates (Difco/Becton Dickinson) and incubated at at $4{ }^{\circ} \mathrm{C}$ and $15^{\circ} \mathrm{C}$ in triplate. When the colonies were fully formed at each temperature, $\mathrm{cfu} / \mathrm{mL}$ was determined.

\section{RESULTS}

\subsection{Schirmacher Oasis.}

3.1.1. Plating. Through the direct spread plate technique, the samples from L27Cand L47 were each plated on R2A agar. It was visually determined that there are many different pigmented bacteria found in L27C and L47 (Figure 3A and Figure 4A). These isolates were further isolated and subcultured (as shown in Figure 3B and Figure 4B). From the L27C samples, there was 17 different isolates were isolated and subcultured. Meanwhile L47 exhibited 10 different isolates (Figure 3B and Figure 4B). 

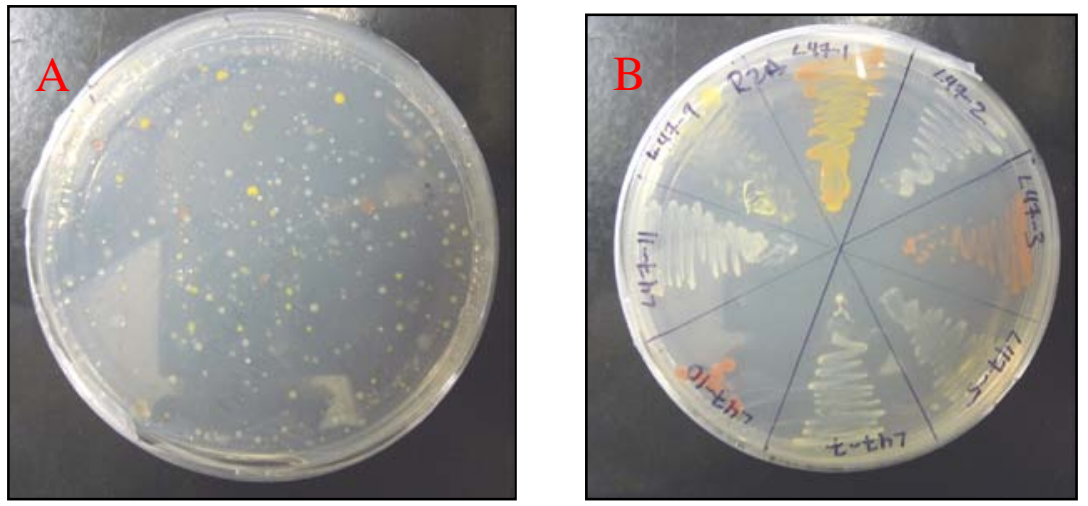

Figure 3: (a) Samples from L47 that were plated on R2A agar and grown at $15^{\circ} \mathrm{C}$. (b) 10 different isolates were subcultured onto fresh R2A agar for further tests.
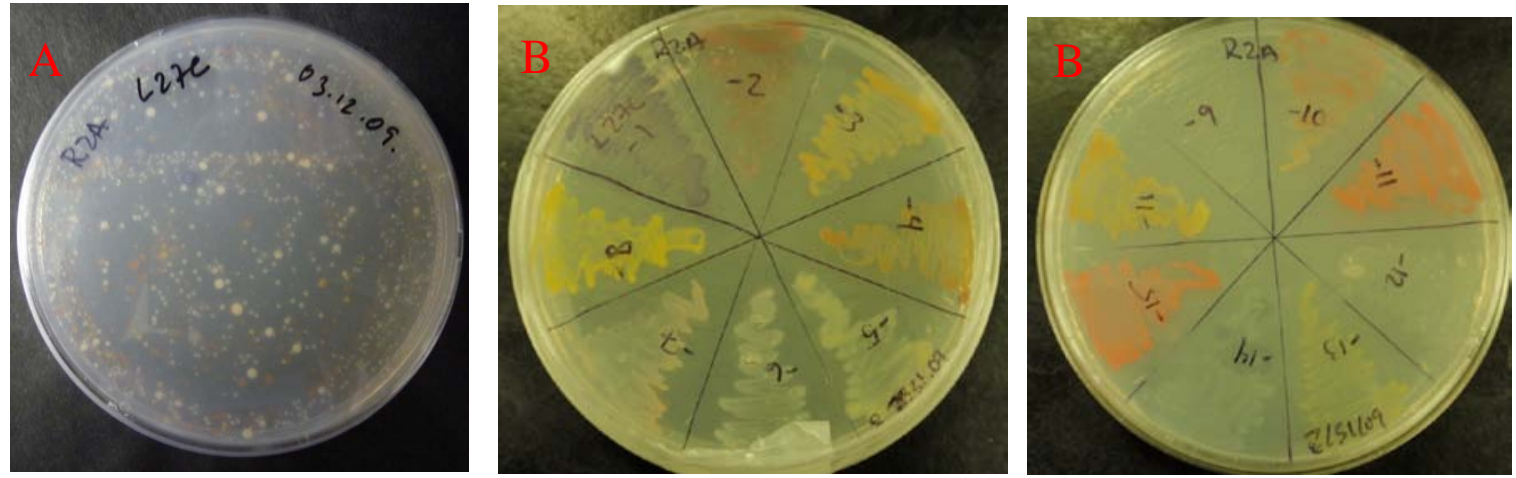

Figure 4: (a) Samples from L27C were plated on R2A agar and grown at $15^{\circ} \mathrm{C}$. (b) 17 different isolates were subcultured onto fresh R2A agar for further analysis.

3.1.2. 16S rRNA culture-dependent methodology. To further identify these organisms, culture-dependent methodology was used. Sequences were subjected to BLAST search (www.ncbi.nlm.nih.gov), then aligned and subsequently phylogenetic trees were created using MEGA 4 software in order to distinguish the different genus each isolate belong to. The diversity of heterotrophic microorganisms found in L27C fell into 4 different phyla including: Proteobacteria, Bacteriodetes, Actinobacteria, and Deinococcus-Thermus (Table 2). The majority of the isolates fell within the Phylum Proteobacteria include the genera Janthinobacterium, Duganella and Sphingamonas. Duganella was the most common genus from L27C with 6 different isolates followed by Sphingamonas (4 isolates), Hymenobacter (2 isolates), and Arthrobacter (2 isolates). The genera Janthinobacterium, Subtercola and Deinococcus were also identified by $16 \mathrm{~S}$ culture-dependent analysis and each contained an isolate. While the diversity of the heterotrophic microorganisms in L47 fell into 3 different phyla including: Proteobacteria, Bacteriodetes and Actinobacteria (Table 3). Similar to L27C, the Phylum Proteobacteria represented the most organisms found in L47. Janthinobacterium and Hymenobacter were the most common (2 isolates each) while Sphingamonas, Rhodopseudomonas/Bradyrhizobium, Massilia, and Cryocola/Salinibacterium were also identified by $16 \mathrm{~S}$ rRNA culture-dependent methodology with one isolate each.

3.1.3. Bacterial enumeration. Enumeration of microbial community found in L27Cand L47 was analyzed by direct plate counts (Table 4). The average cfu/ml between $4^{\circ} \mathrm{C}$ and $15^{\circ} \mathrm{C}$ for $\mathrm{L} 27 \mathrm{C}$ was $1.04 \times 10^{7} \pm 1.5$ $\mathrm{cfu} / \mathrm{ml}$ while the average $\mathrm{cfu} / \mathrm{ml}$ for L47 was $1.1 \times 10^{4} \pm 0.65 \mathrm{cfu} / \mathrm{ml}$. These results are similar to other 
published results for water from Antarctica $10^{2}$ to $10^{7}$ cells $\mathrm{ml}^{-1}$ (Takii et al., 1986; Franzmann et al., 1990) $)^{13,14}$.

Table 2: Isolates subcultured from L27Csamples. These isolates were identified by 16S rRNA gene culture-dependent methodology. The 16S rRNA sequence of each of the isolates were distinguished by utilizing BLAST search, alignment by CLUSTALW, and phylogenetic trees were created by MEGA 4 to identify the most appropriate genus for each isolate.

\begin{tabular}{|c|c|c|c|c|c|c|}
\hline $\begin{array}{l}\text { Bacterial } \\
\text { isolate }\end{array}$ & $\begin{array}{l}\text { Gram } \\
\text { stain }\end{array}$ & Morphology & Color & Phylum & $\begin{array}{c}\text { Closest described } \\
\text { relative }\end{array}$ & \% Identity \\
\hline L27C-1 & - & Bacillus & Purple & \multirow{7}{*}{$\begin{array}{c}\text { Beta-proteobacteria } \\
\text { (Phylum Proteobacteria) }\end{array}$} & Janthinobacterium & 99 \\
\hline L27C-6 & - & Bacillus & White & & Duganella & 99 \\
\hline L27C-9 & - & Bacillus & White & & Duganella & 98 \\
\hline L27C-12 & - & Bacillus & White & & Duganella & 97 \\
\hline L27C-13 & - & Bacillus & Yellow & & Duganella & 97 \\
\hline L27C-14 & - & Bacillus & White & & Duganella & 96 \\
\hline L27C-17 & - & Bacillus & Yellow & & Duganella & 98 \\
\hline L27C-3 & - & Bacillus & Yellow & \multirow{4}{*}{$\begin{array}{l}\text { Alpha-proteobacteria } \\
\text { (Phylum Proteobacteria) }\end{array}$} & Sphingamonas & 99 \\
\hline L27C-4 & - & Coccus & Orange & & Sphingamonas & 99 \\
\hline L27C-8 & - & Coccus & Yellow & & Sphingamonas & 99 \\
\hline L27C-16 & - & Coccus & Yellow/Orange & & Sphingamonas & 99 \\
\hline L27C-2 & - & Bacillus & Red & \multirow{2}{*}{ Bacteroidetes } & Hymenobacter & 93 \\
\hline L27C-10 & - & Bacillus & Light Red & & Hymenobacter & 97 \\
\hline L27C-5 & + & Bacillus & White & \multirow{3}{*}{ Actinobacteria } & Subtercola & 97 \\
\hline L27C-11 & + & Coccus & Red & & Arthrobacter & 98 \\
\hline L27C-15 & + & Coccus & Red & & Arthrobacter & 98 \\
\hline L27C-7 & + & Coccus & Pink & Deinonococcus-Thermus & Deinococcus & 98 \\
\hline
\end{tabular}

Table 3: Isolates subcultured from L47 samples. These isolates were identified by 16S rRNA gene culture-dependent methodology. The 16S rRNA sequence of each of the isolates were distinguished by utilizing BLAST search, alignment by CLUSTALW, and phylogenetic trees were created by MEGA 4 to identify the most appropriate genus for each isolate.

\begin{tabular}{|c|c|c|c|c|c|c|}
\hline $\begin{array}{l}\text { Bacterial } \\
\text { isolate }\end{array}$ & $\begin{array}{l}\text { Gram } \\
\text { stain }\end{array}$ & Morphology & Color & Phylum & Closest described relative & \% Identity \\
\hline L47-1 & - & Bacillus & Orange & \multirow{2}{*}{$\begin{array}{l}\text { Alpha-proteobacteria } \\
\text { (Phylum Proteobacteria) }\end{array}$} & Sphingomonas & 99 \\
\hline L47-6 & - & Bacillus & White & & $\begin{array}{c}\text { Rhodopseudomonas/ } \\
\text { Bradyrhizobium }\end{array}$ & 96 \\
\hline L47-2 & - & Bacillus & White & \multirow{3}{*}{$\begin{array}{c}\text { Beta-proteobacteria } \\
\text { (Phylum Proteobacteria) }\end{array}$} & Janthinobacterium & 99 \\
\hline L47-7 & - & Bacillus & White & & Janthinobacterium & 97 \\
\hline L47-5 & - & Bacillus & $\begin{array}{l}\text { Yellowish- } \\
\text { white }\end{array}$ & & Massilia & 97 \\
\hline L47-3 & - & Bacillus & Red & \multirow{2}{*}{ Bacteroidetes } & Hymenobacter & 96 \\
\hline L47-10 & - & Bacillus & Light Red & & Hymenobacter & 97 \\
\hline L47-9 & + & Bacillus & Yellow & Actinobacteria & Cryocola/Salinibacterium & 96 \\
\hline
\end{tabular}


Table 4: Bacterial enumeration of samples collected from the Schirmacher Oasis by direct plate count method. Cfu/ml was calculated for each plate $(n=3)$ for each of the different samples.

\begin{tabular}{|c|c|c|c|}
\hline Lakes & Type & CFU/ml (n=3) \pm SD & $\begin{array}{c}\text { Types of bacterial } \\
\text { colony-count }\end{array}$ \\
\hline L47 & Land-locked & $1.1 \times 10^{4} \pm 0.65$ & 10 \\
\hline L27C & Land-locked & $1.04 \times 10^{7} \pm 1.5$ & 17 \\
\hline
\end{tabular}

3.2. Lake Untersee. Compared to the samples from the Schirmacher Oasis (open lake system) there was low amount of microbial diversity and enumeration found in the closed system Lake Untersee. Samples from Lake Untersee were collected at different depths but only 70 meter sample displayed a significant amount of microbes (Table 5). Because of the lack of growth at all other depths besides 70 meters, $16 \mathrm{~S}$ rRNA gene culture-dependent methodology was only used on the samples from this depth. Sequencing revealed two different phyla from the samples from Lake Untersee: Proteobacteria and Bacteriodetes. Both phyla were equally prevalent in the samples isolated from Lake Untersee. Flavobacterium was the most abundant ( 3 isolates) followed by Polaromonas ( 2 isolates) and Rhodoferax (1 isolate).

Table 5: Bacterial enumeration by direct plate count for samples collected at different depths of Lake Untersee. Plates were incubated at $4^{\circ} \mathrm{C}$ until growth was visible.

\begin{tabular}{|c|c|c|}
\hline Depth & $\mathbf{C f u / m l}$ & $\begin{array}{c}\text { Types of bacterial } \\
\text { colonies - count }\end{array}$ \\
\hline $20 \mathrm{~m}$ & $3.5 \times 10^{1}$ & 1 \\
\hline $45 \mathrm{~m}$ & $8.67 \times 10^{1}$ & 3 \\
\hline $65 \mathrm{~m}$ & 0 & 0 \\
\hline $70 \mathrm{~m}$ & $1.775 \times 10^{3}$ & 6 \\
\hline
\end{tabular}

Table 6: Isolates subcultured from Lake Untersee at 70 meters depth. These isolates were identified by 16S rRNA gene culture-dependent methodology. The 16S rRNA sequence of each of the isolates were distinguished by utilizing BLAST search, alignment by CLUSTALW, and phylogenetic trees were created by MEGA 4 to identify the most appropriate genus for each isolate.

\begin{tabular}{|c|c|c|c|c|c|c|}
\hline $\begin{array}{c}\text { Bacterial } \\
\text { isolate }\end{array}$ & $\begin{array}{l}\text { Gram } \\
\text { stain }\end{array}$ & Morphology & Color & Phylum & $\begin{array}{c}\text { Closest described } \\
\text { relative }\end{array}$ & \% Identity \\
\hline U1b & - & Bacillus & White & \multirow{2}{*}{$\begin{array}{c}\text { Alpha- } \\
\text { proteobacteria } \\
\text { (Phylum } \\
\text { Proteobacteria) }\end{array}$} & Polaromonas & 98 \\
\hline U4b & - & Bacillus & White & & Polaromonas & 98 \\
\hline U3b & - & Bacillus & White & $\begin{array}{c}\text { Beta- } \\
\text { proteobacteria } \\
\text { (Phylum } \\
\text { Proteobacteria) }\end{array}$ & Rhodoferax & 98 \\
\hline $\mathrm{U} 2 \mathrm{~b}$ & - & Bacillus & Yellow & \multirow{3}{*}{ Bacteroidetes } & Flavobacterium & 97 \\
\hline U5b & - & Bacillus & Yellow & & Flavobacterium & 95 \\
\hline U6b & - & Bacillus & Yellow & & Flavobacterium & 95 \\
\hline
\end{tabular}

\section{DISCUSSION}

The primary objective of this study was to assess the microbial diversity between the Schirmacher Oasis (open system) and Lake Untersee (closed system). Using culture-dependent methodology and 16S rRNA 
gene the open water lake system of Schirmacher Oasis has a greater microbial diversity and enumeration than the closed system in Lake Untersee. Between L27Cand L47, there were 5 different phyla and 10 different genera while Lake Untersee only possessed 2 different phyla and 3 different genera. Interestingly there was no common genus between the Schirmacher Oasis and Lake Untersee. This may be due to sample size as there are over 180 different freshwater lakes in Schirmacher Oasis but only 2 were investigated in this study. As expected, the open water lake system of Schirmacher Oasis has a much greater microbial diversity and enumeration compared to the closed water system of Lake Untersee. This disparity may be due to the mixing of microbes through the surface channels or by catabolic winds and higher level of nutrient availability. Another reason for the low amount of microbes found in Lake Untersee may be due to its intriguing $\mathrm{pH}$ variability.. The $\mathrm{pH}$ measured in situ differs from the $\mathrm{pH}$ measured after the water sample is collected. Lake Untersee may have a biologically driven $\mathrm{pH}$ system.

A other objective of this study is to determine if the microbial diversity between the freshwater land-locked lakes of Schirmacher Oasis have similar microbial profiles. In this study, we have examined two freshwater land-locked lakes: L27C and L47. These two freshwater lakes are separated by a glacier but surface channels and catabolic wind allow for intermixing between these lakes. The microbial diversity of L27C contained 7 different genera while L47 contained 6 different genera. The common genera between L27C and L47 were Sphingamonas, Janthinobacterium, and Hymenobacter. L27C also contained the following genera that were not found in L47: Duganella, Subtercola, Arthrobacter, and Deinococcus. Additionally, the genera Massilia, Rhodopseudomonas/Bradyrhizbium and Cryocola/Salinibacterium were identified in L47 but not in L27C. These different microbial communities may be due to the difference in $\mathrm{pH}$ between L27C (pH 9.1) and L47 (pH 5.7) (Table 1). Such a large difference in $\mathrm{pH}$ could determine which microbes can adapt and survive in each environment. Some microorganisms are able to withstand a wide $\mathrm{pH}$ range and thus there are some similarities between the microbial diversity of L27C and L47. Due to the lack of specificity of 16S rRNA gene used as a marker, further biochemical tests are needed to distinguish between closely related genera such as Rhodopseudomonas and Bradyrhizobium or Masillia from Janthinobacterium and Duganella.

Biological pigments in extremophile microorganisms in Antarctica have been shown to absorb a wide spectrum of visible and UV lights. These pigments have been hypothesized to play important role in the adaptation of these microorganisms in high Antarctic solar radiation environment. As shown in Figure 3a and Figure 4a, there are a considerable number of pigmented bacteria found on the agar plates. These colors include red, yellow, orange, purple, pink, and white. Furthermore, Mueller et al., suggested that some of these pigments may help prevent anti-oxidative stress $(2005)^{16}$. Additionally these pigments may have clinical significance . Mojib et al., (2010) ${ }^{15}$ showed that the pigments extracted from Janthinobacterium sp. and Flavobacterium sp. have antimicrobial effect against certain Mycobacterium.

Further study is needed for a complete understanding of the microbial community by comparing microbial diversity using culture-independent methodologies. It has been suggested that only $1-10 \%$ of total microbial load can be detected by culture based approach (Cowan et al. 2007) ${ }^{17}$. Utilizing both culture-independent and culture-dependent methodologies would allow for a more complete study in determining microbial diversity in Antarctic freshwater lakes.

\section{ACKNOWLEDGEMENTS}

We thank Tawani Foundation of Chicago; NASA's Exobiology program (grant \#NNX08AO19G), and Astrobiology Program (Grant \#NNX07AD90A) for supporting the Tawani 2008 International Antarctic Scientific Expedition; We are grateful to Colonel (IL) J.N. Pritzker IL ARNG (Retired) for the leadership and supporting the expedition; Logistics support was provided by the Arctic and Antarctic Research Institute/Russian Antarctic Expedition (AARI/RAE); Antarctic Logistics Centre International (ALCI), Cape Town, SA; Von Braun Center for Science Innovation, Inc (VCSI, Inc.); National Space Science Technology (NSSTC), NASA; Rasik Ravindra (Director) of National Center for Antarctic and Ocean Research (NCAOR); 2008-2009 Maitri staffs and Cdr. Arun Chaturvedi and Cdr. Pradip Malhotra and personnel at Novolazarevskaya Station, Russia. We also thank Ed Tracy of Tawani Foundation, Marty Kress of VCSI, Inc., and Robert Fischer of Biology, UAB for the support; special thanks to Art Mortvedt for the field logistic support and Mark Roderer for the logistic support from Cape Town, South Africa base camp during the expedition. 


\section{REFERENCES}

[1] Ekelöf, E., “Bakteriologische studien wahrend der Schwedishen Sudpolar expedition 1901-1903,” In: Wissenschaftiche Ergebnisse der Schwedischen sudpolar Expedition 1901-1903, O. Nordenskjold (ed.). Lithogr. Inst. Generalstabs, Stockholm (1908a).

[2] Ekelöf, E., "Studien uber den Bakteriengehalt der luft und des Erdbodeus der antarktishen Gegenden, ausgefi ihrt wahrend der schwedischen sudpolar expedition 1901-1903,” Z. Hyg. Infekt. 56, 344-370 (1908b).

[3] Pirie, J.H.H., “First Antarctic voyage of the Scotia,” J. Bacteriol. Scottish Geog. Mag. 20, 129-132 (1904).

[4] Pirie, J.H.H., "Notes on Antarctic bacteriology,” Report of the Scientific Results of the S.Y. Scotia, Vol. 3, pp. 157168 (1912).

[5] Gazert, H., “Undersuchungen uber Meeresbakterien und chren Einfl uss auf den Stoffweckselim Meer,”Deutschi Biidpolar Expedition. 1901-1903 Berlin, 7,268-296 (1912).

[6] McLean, A.L., “Bacteria of ice and snow in Antarctica,” Nature 102, 35-39 (1918a).

[7] McLean, A.L., "Bacteriological and other researches Australian Antarctic Expedition 1911-1914,” Scient. Rep. 7, 1-128. (1918b).

[8] Flint, E.A. and J.D. Stout, “Microbiology of some soils from Antarctica,” Nature 188, 767-768 (1960).

[9] Shivaji, S., Reddy, G.S.N., Prasad, R.A., Kutty, R. and Ravenschlag, K., "Bacterial diversity of a soil sample from Schirmacher Oasis, Antarctica,” Cell. Mol. Biol., 50,525-536 (2004).

[10] Huang, J.P., Swain, A.K., Hoover, R.B., Andersen, D.T., and Bej, A.K., "Heterotrophic Microbial Diversity in a Previously Undescribed Freshwater Land-locked Lake Tawani in Schirmacher Oasis, Antarctica,” (2010) (in preparation)

[11] Matondkar, S.G.P. "Microbiological studies in Schirmacher Oasis, Antarctica: Effect of temperature on bacterial populations,” Third Indian Expedition to Antarctica, Scientific Report. 3. 133-147 (1986).

[12] Martinez-Murcia, A.J., Anton, A.I. and Rodriguez-Valera, F., "Patterns of sequence variation in two regions of the 16S rRNA multigene family of Escherichia coli,” Int. J. Syst. Bacteriol. 49, 601-610 (1999).

[13] Takii, S., Konda, T., Hirasishi A., Matsumotgo, I., Kawano, T., and Torii, T. "Vertical distribution in and isolation of bacteria from Lake Vanda; An Antarctic lake,” Hydrobiologia. 135. 15-21 (1986).

[14] Franzmann, P.D., Deprez, P.P., McGuire, A.J., McMeekin, T.A., and Burton, H.R., “The heterotrophic, bacterial microbiota of Burton Lake, Antarctica,” Polar Biology. 10. 261-264 (1990).

[15] Mojib, N., Philpott, R., Huang, J.H., Niederweis, M., and Bej, A.K., “Antimycobacterial activity in vitro of pigments isolated from Antarctic bacteria,” Antonie Leeuwenhoek. 97. (2010).

[16] Mueller, D.R., Vincent, W.F., Bonilla, S., and Laurion, I. “Extremotrophs, extremophiles and broadband pigmentation strategies in a high arctic ice shelf ecosystem,” FEMS MICROBIOL ECOL. 53. 73-87 (2005).

[17] Cowan, D.A., Casanueva, A., and Stafford, W. [Physiology and Biochemistry of Extremophiles], ASM Press, Washington, D.C., 119-132 (2007). 